\title{
Harmonization of the National Legislation on Cosmetic Products in the Context of the Standardization of the European Legislation in the Field
}

\author{
Cristina-Luiza Erimia \\ "Ovidius" University of Constanta, Faculty of \\ Pharmacy, Constanta, Romania
}

\section{Abstract}

Considering the concern of the European Union to implement an internal market for cosmetic products which also ensures a high level of human health protection and that cosmetics is one of the industrial activities in the EU affected by counterfeiting, which may increase the risks to human health, this article examines how European horizontal legislation is implemented in national law. This article aims to present the legal instruments created at EU level to consolidate the safety of cosmetic products and to strengthen the surveillance of the cosmetic products introduced on the market, but also to protect consumers, taking into account that in order to ensure an effective control of the market it is necessary to have a high degree of administrative cooperation between the competent authorities of the Member States. Moreover, the article aims to present the active role undertaken by the cosmetics industry in developing alternative testing methods within the Horizon 2020 Programme.

Keywords: European legislation, the safety of cosmetic products, European market, consumer protection, harmonization of national legislation

\section{Introduction}

The first European regulation of cosmetic products it was made by Directive 76/768/ of Council of 27 July 1976, on the approximation of the laws of the Member States relating to cosmetic products [1]. The need for a European legislative framework in the field of cosmetics was hindered by disparities between certain national provisions which directly affect the functioning of the internal market, by imposing to cosmetic producers to vary their production according to the Member State for which the products were intended.

Therefore, the regulation at EU level of this area and the adoption of a European model in which to inspire Member States in the action of modernization of national legislation, since this objective to be achieved by means which take account of 
technological and economic specific requirements of Member States.

\section{Theory}

Since Council Directive 76/768/EEC has been significantly amended on several occasions it had to be recast as one single text in the interests of clarity. The appropriate legal instrument in this situation was a Regulation because it imposes clear and detailed rules which do not give room for diverging transposition by Member States. Moreover, a Regulation ensures that legal requirements are imple-mented at the same time throughout the Community.

Therefore, on 30 November 2009, the European Parliament and the Council of the European Union, having regard to the opinion of the European Economic and Social Committee [2], has adopted Regulation (EC) no 1223/2009 on cosmetics products [3], which aims to simplifying procedures and streamlining terminology, thereby reducing administrative burden and ambiguities.

This Regulation comprehensively harmonises the rules in the Community in order to achieve an internal market for cosmetic products while ensuring a high level of protection of human health. The environmental concerns that substances used in cosmetic products may raise are considered through the application of Regulation (EC) No 1907/2006 concerning the Registration, Evaluation, Authorisation and Restriction of Chemicals (REACH) and establishing a European Chemicals Agency [4], which enables the assessment of environmental safety in a cross-sectoral manner.

\section{Results and Discussion}

Because the European cosmetics sector is one of the industrial activities affected by counterfeiting, which may increase risks to human health, Member States should pay particular attention to the implementation of horizontal Community legislation and measures regarding counterfeit products in the field of cosmetic products, for example Council Regulation (EC) No 1383/2003 [5] of 22 July 2003 concerning customs action against goods suspected of infringing certain intellectual property rights and the measures to be taken against goods found to have infringed such rights and Directive 2004/48/EC [6] on the enforcement of intellectual property rights. Regarding on animal testing and alternative methods, animal welfare has been enshrined by article 13 of the Treaty on the Functioning of the European Union (TFEU) [7] as a European value taken into account in EU policies.

Council Directive 86/609/EEC [8] regarding the protection of animals used for experimental and other scientific purposes, in particular, article 7 , requires that animal experiments be replaced by alternative methods, where such methods exist and are scientifically satisfactory. Animal testing of finished cosmetic products in the Union has been prohibited since 2004 and of cosmetic ingredients since March 2009

In order to meet the requirements of the Directive, as from 11 March 2009, it is also prohibited to market in the Union cosmetic products and their ingredients which have 
been tested on animals. This marketing ban applies to all but the most complex human health effects to be tested to demonstrate the safety of cosmetic products (repeateddose systemic toxicity, skin sensitisation, carcinogenicity, reproductive toxicity and toxicokinetics), for which the European Parliament and the Council extended the deadline to 11 March 2013. The Cosmetics Regulation, which repeals and replaces the Cosmetics Directive as of 11 July 2013, contains the same provisions. The testing and marketing bans apply even in case alternative methods to animal testing are not yet available. This reflects a sector-specific political choice by the European Parliament and the Council. Other Union legislation recognises that animal testing is still needed in the absence of alternative methods to ensure the protection of human health and the environment, but sets very high animal welfare standards for such testing and requires that whenever possible testing is replaced, reduced and refined.

Regarding availability of alternative methods, the Commission has provided a report to the European Parliament and the Council in September 2011 [9], based on a comprehensive technical report which was the result of wide scientific input and a public consultation [10].

The basic findings of this technical report, which are still valid, highlights that complete replacement of tests regarding the parameters of prohibited trading with effect from the 2013 through alternative methods is not yet possible for all parameters [11].

For the outstanding complex endpoints replacement will not be achieved by replacing one animal test with one in vitro test. Replacement can only be achieved through integrated testing strategies, combining several in vitro and in silico approaches.

A more comprehensive description of progress being made in the development, validation and regulatory acceptance of alternative methods in the different toxicological areas was provided in the ECVAM technical report 2013 [12],

\section{Conclusions}

The Union wishes to set an example of responsible innovation in cosmetics without new dedicated animal tests. It is therefore crucial to continuously support the research and development of methods to better assess human safety and capitalize on past efforts by ensuring that the latest scientific advances are translated into animal-free solutions.

There are compelling reasons for a strong international cooperation on the development of alternative test methods for cosmetics [13]. Cosmetic products and their ingredients are traded worldwide and the Union is home to some of the worldleading brands in the cosmetics field. A common understanding of the safety assessment for cosmetics and acceptance of alternative methods will improve human safety, help animal welfare and trade, but cooperation is also a must because the underlying scientific challenges are far too big to be shouldered by one region alone. Cooperation at the research level is therefore a first important step. 
In the field of cosmetics, the International Collaboration on Cosmetics Regulation (ICCR) provides an important forum for cooperation between the United States of America, Canada, Japan and Europe [14]. Alternatives to animal testing have been a key focus since the inception of ICCR. ICCR has recently started work on in silico (computational) prediction models, something that in addition to in vitro methods is of central importance in advancing alternative safety assessment approaches.

The marketing ban gives an important signal, not only in relation to the value attached to animal welfare in the European Union, but also in relation to the overall paradigm shift in relation to human safety assessment.

\section{References}

[1] Directive 76/768/ of Council of 27 July 1976, on the approximation of the laws of the Member States relating to cosmetic products, published in the Official Journal of the European Union L 157 of 30.4.2004.

[2] The opinion of the European Economic and Social Committee was published in the Official Journal of the European Union C 27 of 3.2.2009, p. 34.

[3] Regulation (EC) no 1223/2009 of the European Parliament and the Council of the European Union on cosmetics products, published in the Official Journal of the European Union L 342 of 22.12.2009.

[4] Regulation (EC) No 1907/2006 of the European Parliament and of the Council of 18 December 2006 concerning the Registration, Evaluation, Authorisation and Restriction of Chemicals (REACH) and establishing a Euro- pean Chemicals Agency, published in the Official Journal of the European Union L 396 on 30.12.2006.

[5] Council Regulation (EC) No 1383/2003 of 22 July 2003 concerning customs action against goods suspected of infringing certain intellectual property rights and the measures to be taken against goods found to have infringed such rights, published in the Official Journal of the European Union L 196 on 2.8.2003.

[6] Directive 2004/48/EC of the European parliament and of the Council of 29 April 2004 on the enforcement of intellectual property rights, published in the Official Journal of the European Union L 157 on 30.4.2004.

[7] Treaty on the Functioning of the European Union (TFEU) - consolidated version, published in the Official Journal of the European Union C 326 on 26.12.2012.

[8] Council Directive 86/609/EEC of 24 November 1986 on the approximation of laws, regulations and administrative provisions of the Member States regarding the protection of animals used for experimental and other scientific 
purposes, published in the Official Journal of the European Union L 358 0n 18.12.1986.

[9] Report on the Development, Validation and Legal Acceptance of Alternative Methods to Animal Tests in the Field of Cosmetics (2009), 13.9.2011, COM (2011) 558 final, Bruxelles, 13.9.2011.

[10] Alternative (non-animal) methods for cosmetics testing: current status and future prospects-2010, available at:

http://ec.europa.eu/consumers/sectors/cosmetics/files/pdf/animal testing/fin al report at en.pdf,

[11] Communication from the Commission to the European Parliament and the Council on animal testing and marketing ban current situation of alternative test methods cosmetics, COM (2013) 135 final, Brussels, 11.3.2013.

[12] Available at:

http://ec.europa.eu/consumers/sectors/cosmetics/documents/animaltesting/index_en.htm

[13] Proposal for a Regulation of the European Parliament and of the Council establishing Horizon 2020 - The Framework Programme for Research and Innovation (2014-2020), COM (2011) 809 final, Brussels, 30.11.2011.

[14] Communication from the Commission, Europe 2020 Flagship Initiative, Innovation Union, COM (2010) 546 final, Brussels, 6.10.2010. 